receiving $3 \mathrm{mg} / \mathrm{kg}$ injections significantly increased for 8 weeks from $21 \pm 2$ to $56 \pm 9 \mathrm{~mm} \mathrm{Hg}, 12 \pm 2$ to $37 \pm 6 \mathrm{~mm}$ $\mathrm{Hg}$, and $344 \pm 130$ to $2254 \pm 425$ dyne $\cdot \mathrm{sec} \cdot \mathrm{cm}^{-5}$, respectively. The cardiac output was significantly reduced from $1.6 \pm 0.3$ to $1.0 \pm 0.2 \mathrm{~L} / \mathrm{min}$ in beagles receiving 3 $\mathrm{mg} / \mathrm{kg}$ injections. However, these changes in beagles receiving $1.5 \mathrm{mg} / \mathrm{kg}$ injections were not so marked. The heart rate, mean arterial pressure, right atrial pressure, and pulmonary capillary wedge pressure remained relatively stable throughout the study period. The oxygen saturation significantly decreased from $99 \% \pm 1 \%$ to $94 \% \pm 3 \%$ in beagles receiving $3 \mathrm{mg} / \mathrm{kg}$ injections. Gross pathologic evaluation revealed that the right ventricles were enlarged and the weight ratio of the right to left ventricle increased from $0.38 \pm 0.07$ to $0.50 \pm 0.07$ in beagles receiving $3 \mathrm{mg} / \mathrm{kg}$ injections. On histologic study, the right ventricular sections showed moderate myocyte hypertrophy and the thickness of the media in small pulmonary arteries was increased. Our data suggested that beagles treated with a $3.0 \mathrm{mg} / \mathrm{kg}$ injection of DMCT produced a unique, relatively noninvasive model of $\mathrm{PH}$. There was a close correlation between the dose of DMCT and the severity of induced disease.

Heart-lung transplantation has become a routine procedure in the treatment of patients with end-stage $\mathrm{PH}$. Recently, because of serious shortages of heart-lung blocks, single lung transplantation has been promoted as a possible alternative to heart-lung transplantation for endstage pulmonary vascular disease of either primary or secondary causes. ${ }^{4,5}$ Despite clinical success with single lung transplants for $\mathrm{PH}$, many problems remain to be solved. An interesting question is whether combined heart-lung, isolated single, or bilateral lung transplantation would be preferable for the treatment of patients with
PH. In clinical lung transplantation for end-stage pulmonary vascular disease, cardiopulmonary bypass is necessary during the procedure. Although lung transplantation in rats with $\mathrm{PH}$ has been investigated, rats are too small to be subjected to such circulatory assistance. For this reason a design for a new experimental model to induce $\mathrm{PH}$ in a larger animal is of vital importance for transplantation basal study. Furthermore, these relatively large animal models, in which hemodynamics can be measured accurately, are considered to be valuable for further studies not only on transplantation but also on pharmacology. We have now used this model to study relevant physiology and pathophysiology in $\mathrm{PH}$ and right ventricular function.

\section{REFERENCES}

1. Hayashi Y, Hussa JF, Lalich JJ. Cor pulmonale in rats. Lab Invest 1967;16:875-81.

2. Rabinovitch M, Gamble W, Nadas AS, Miettinen OS, Reid L. Rat pulmonary circulation after chronic hypoxia: hemodynamic and structural features. Am J Physiol 1979;236:H818-27.

3. Mattocks AR. Dihydropyrrolizidine derivatives from unsaturated pyrrolizidine alkaloids. J Chem Soc 1969; 8:1155-62.

4. Levine SM, Gibbons WJ, Bryan CL, et al. Single lung transplantation for primary pulmonary hypertension. Chest 1990;98:1107-15.

5. Pasque MK, Kaiser LR, Dresler CM, Trulock E, Triantafillou AN, Cooper JD. Single lung transplantation for pulmonary hypertension. J ThORAC CARDIoVASC SURG 1992;103:475-82.

\title{
A TECHNIQUE TO MINIMIZE AIR LEAKAGE AFTER EXCISION OF EMPHYSEMATOUS BULLA OF THE LUNGS
}

\author{
Iwao Takanami, MD, Yasuki Yamamoto, MD, Tatsuya Yamamoto, MD, and Susumu Kodaira, MD, Tokyo, Japan
}

If pulmonary plication is done to treat an emphysematous bulla, pulmonary fistulae are sometimes formed and persist for long periods. ${ }^{1}$ We recently established a technique to easily reduce postoperative air leakage with the use of bioabsorbable polyglactin 910 (Vicryl mesh; John-

From the First Department of Surgery, Teikyo University of School of Medicine, 2-11-1 Kaga Itabashi-Ku, Tokyo 173, Japan.

J THORAC CARDIOvasc SuRg 1995;110:547-8

Copyright (C) 1995 by Mosby-Year Book, Inc.

$0022-5223 / 95 \$ 3.00+0 \quad \mathbf{1 2 / 5 4 / 6 2 1 0 3}$ son \& Johnson Cardiovascular, King of Prussia, Pa.), a GIA $8 \mathrm{~cm}$ linear stapling device (United States Surgical Corporation, Auto Suture Company Division, Norwalk, Conn.), and fibrin glue (Bolheal; Teijin, Inc., Tokyo, Japan).

Several strips of absorbable polyglactin $910(1 \mathrm{~cm}$ wide and $8 \mathrm{~cm}$ long) were prepared. One of these strips was bonded by fibrin glue onto both sides of the GIA linear stapling device (the cartridge side and the front side) (Fig. 1). The bulla was lifted by pulmonary forceps until it had a tentlike appearance. The stapling device to which strips of polyglactin 910 had been bonded was applied across the pulmonary base that was to be resected. The stapler was then used to resect the target tissue. In cases in which the 


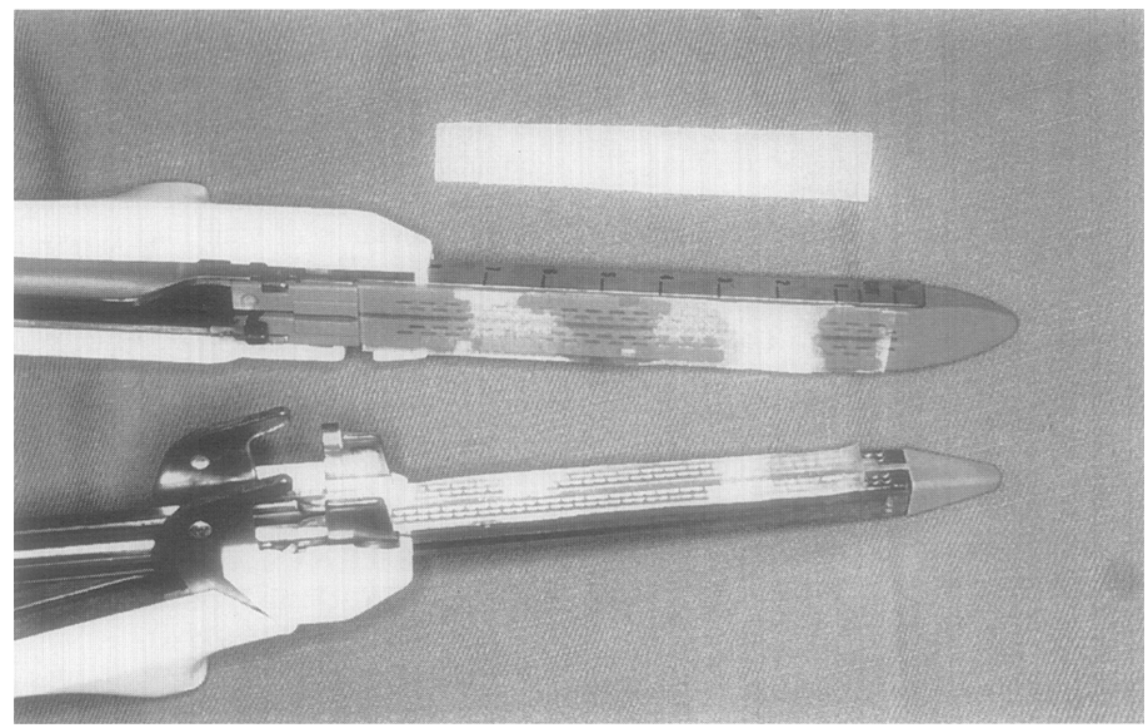

Fig 1. Polyglactin 910 bonded by fibrin glue to linear stapling device.

tissue to be resected was longer than $8 \mathrm{~cm}$, the portion of the target tissue that remained unresected was resected with the use of another stapler to which strips of polyglactin 910 had been bonded. The unconsumed portion of the fibrin glue was applied to the resected area.

Emphysematous bullae often affect the entire lungs. For this reason, the percentage of patients with this condition who are eligible for operation is relatively low. However, lung plication is needed in cases in which a giant bulla compresses the normal area of the lung, causing dyspnea, or in cases of intractable bullae in which a thoracic drain needs to be used for long periods because of pneumothorax. ${ }^{1,2}$ When plication is performed or a stapling device is applied for cases of pulmonary bulla, air leakage through the needle holes often occurs, leading to persistent pulmonary fistulas. Various techniques to avoid this problem have been reported. Juettner and associates ${ }^{3}$ used absorbable polydioxanone ribbons and a stapling device to avoid air leakage. According to our experience, their technique involves two problems: (1) it is difficult to manipulate the stapling device while keeping the ribbon on the excision line of the lung and (2) the excessive portion of the ribbon needs to be cut with scissors. Cooper ${ }^{4}$ reported a technique that uses bovine pericardial strips and a GIA stapling device (United States Surgical Corporation, Auto Suture Company Division, Norwalk, Conn.). With his technique, bovine pericardial strips are first placed on the stapling device. They are then tied with a catgut thread. The bulla is resected with the stapler and the catgut thread is removed. Connolly and Wilson ${ }^{1}$ reported a technique by which a Teflon felt piece is placed on the stapling device and fixed with adhesive strips. Our technique uses absorbable polyglactin 910 strips to avoid pulmonary fistulas. The strips are bonded by fiblin glue to a stapling device.

If absorbable polyglactin 910 can be preoperatively cut into strips and if these strips can be preoperatively bonded by glue to a disposable sheath for subsequent sterilization, the operation will be simpler. Our technique is also applicable to thoracoscopic partial resection of emphysematous lung tissue. For lung operations under thoracoscopic guidance, it is desirable to minimize manipulations within the thoracic cavity. In this respect, our technique, which requires less manipulation within the thoracic cavity, seems to be more useful for thoracoscopic lung operations in comparison with the techniques reported by others.

\section{REFERENCES}

1. Connolly JE, Wilson A. The current status of surgery for bullous emphysema. J THORAC CARDIOVASC SURG 1989;97:351-61.

2. Fitzgerald MX, Keelan PJ, Cugell DW, Gaensler EA. Long-term results of surgery for bullous emphysema. $\mathbf{J}$ ThORAC CARDiovasc SURG 1974;68:566.

3. Juettner FM, Kohek P, Pinter H, Kepp G, Frieks G. Reinforced staple line in severely emphysematous lungs. J Thorac Cardiovasc Surg 1989;97:362-3.

4. Cooper JD. Technique to reduce air leaks after resection of emphysematous lung. Ann Thorac Surg 1994; 57:1038-9. 